\title{
Parental Attachment and Psychological Wellbeing in Adolescents: Mediating Role of Self-esteem
}

\author{
Dharvinder Singh', Karuna Gupta ${ }^{2}$, Arti Bakhshi \\ ${ }^{1,2}$ Lecturer, ${ }^{3}$ Professor, Department of Psychology, University of Jammu, Jammu \& Kashmir, India. \\ DOI: https://doi.org/10.24321/2349.2880.202103
}

\section{I $\quad \mathbf{N} \quad \mathbf{F} \quad \mathbf{O}$}

\section{Corresponding Author:}

Dharvinder Singh, Department of Psychology,

University of Jammu, Jammu \& Kashmir, India.

E-mail Id:

darpan813@gmail.com

Orcid Id:

https://orcid.org/0000-0002-8479-1393

How to cite this article:

Singh D, Gupta K, Bakhshi A. Parental Attachment and Psychological Wellbeing in Adolescents: Mediating Role of Self-esteem. Ind J Youth Adol Health. 2021;8(1):13-17.

Date of Submission: 2021-03-03

Date of Acceptance: 2021-03-23

\section{$\begin{array}{llllllll}\mathbf{A} & \mathbf{B} & \mathbf{S} & \mathbf{T} & \mathbf{R} & \mathbf{A} & \mathbf{C} & \mathbf{T}\end{array}$}

\begin{abstract}
Introduction: Adolescence is amongst the most rapid stage of human development. It is the period to create knowledge and skills, learn to mange emotions, obtain attributes and capacities and relationships with parents and peers. All these aspects are important for enjoying these years and assuming the roles of adults. The purpose of the study was to examine the relationship between parental attachment, self-esteem and psychological wellbeing of adolescents.
\end{abstract}

Methods: The participants were 292 adolescents with age ranging from 13 to 18 years. Inventory for parent and peer attachment (IPPA) by Armsden and Greenberg self-esteem scale by Rosenberg and psychological wellbeing scale by Ryff were used to measure the parental attachment, self-esteem, and psychological wellbeing in adolescents.

Result: Results indicated that the the correlation value of parental attachment and psychological wellbeing was found be 0.306 . The value of correlation value for self-esteem and psychological wellbeing was found to be 0.342 .

Conclusion: Significant positive relationship was found between parental attachment, self-esteem, and psychological wellbeing. The mediation analysis has shown that self-esteem partially mediates the relationship between parental attachment and psychological wellbeing among adolescents.

Keywords: Parental Attachment, Self-esteem, Psychological Wellbeing, Adolescents, Mediation Analysis

\section{Introduction}

Adolescence is a vital and transitional stage of life that connects childhood to adulthood. Most of the physical, intellectual, social, and moral developments take place during this stage. Adolescents are generally perceived as a healthy age group, yet $20 \%$ of them, experience a mental health problem, most commonly depression or anxiety. ${ }^{1}$ These mental health problems are also common among the general adolescent population in India. Early detection and effective intervention will result in better wellbeing of the future citizens of the country. ${ }^{2}$

According to Deci \& Ryan, ${ }^{3}$ psychological wellbeing is usually considered as some combination of positive affective states, for example, happiness (the hedonic perspective) and functioning with optimal effectiveness in individual as well as social life (the eudaimonic perspective). The psychological wellbeing of an individual refers to the wellness and stability of an individual's self. Ryff ${ }^{4}$ gave 
a model of psychological wellbeing that explains it in a positive manner where individual multi-factors contribute meaningfully to a protective personality. Understanding the wellbeing of adolescents and the factors that contribute to it will help towards explaining and defining ways to better help adolescents prepare for adult life. ${ }^{5}$

In the adolescence stage, attachment with parents plays a significant role in the development of self-esteem and overall wellbeing. Attachment is defined as a "lasting psychological connectedness between human beings". ${ }^{6}$ This ethological theory of attachment is the most widely recognised perspective of an infant's emotional tie to the parental figure. ${ }^{7}$ According to this theory, attachment is the principal bond between parents and infant that is fundamental to survival and development. Parents prove to be of lasting importance for the wellbeing of their grownup youths. For teenagers, the parental bond appears to be as significant for their wellbeing as having a partner or a best friend. ${ }^{8}$

Self-esteem is simply how much we perceive ourselves positively or negatively. It is our overall attitude towards ourselves. ${ }^{9}$ Rosenberg ${ }^{10}$ defined self-esteem as a favourable or unfavourable attitude toward the self. Personality constructs such as high self-esteem have seemed to act as protective factors against psychopathology in younger people. Previous research on the association between general wellbeing and personality in adolescents has also demonstrated that there is a strong relationship between self-esteem and general wellbeing. ${ }^{11}$ Children and adolescents whose parents are warm as well as accepting and who have reasonable expectations for mature behaviour feel particularly good about themselves. ${ }^{12}$

Armsden, and Greenberg ${ }^{13}$ stated that adolescents with a higher level of attachment to their parents tend to have a higher level of self-esteem. Yaacob ${ }^{14}$ reported that there was a significant relationship between parentadolescent relationships and self-esteem in adolescents. Anyanwu ${ }^{15}$ stated that parental relationship with their children had predicted adolescents' psychological wellbeing (personal, social, and emotional) in south-eastern Nigerian adolescents. Avci, Yilmaz, and $\mathrm{Koc}^{16}$ also reported that there was a significant positive relationship between subjective wellbeing and self-esteem of nursing students. Abubakar et al. ${ }^{17}$ found that both parents and peer attachment had a significant relationship with the psychological wellbeing of adolescents.

Nwankwo, Okechi and Nweke ${ }^{18}$ concluded that perceived self-esteem and psychological wellbeing were related in student athletes. Schilling ${ }^{19}$ also reported that selfesteem was significantly and positively related to all the six subscales of psychological wellbeing. People with higher self-esteem scored higher on all subscales of psychological wellbeing. Bajaj, Gupta and Pande ${ }^{20}$ found that self-esteem was associated with affect and mental wellbeing in Indian undergraduate university students.

Poudel, Gurung and Khanal ${ }^{21}$ examined the mediating role of self-esteem in the relationship between perceived social support and psychological wellbeing among 348 Nepalese adolescents. It was found that perceived social support indirectly affected the psychological wellbeing of adolescents through self-esteem as a mediating variable.

Based on the previous related literature, it was hypothesised.

$\mathbf{H}_{\mathbf{1}}$ : There is a significant relationship between parental attachment and psychological wellbeing in adolescents.

$\mathbf{H}_{2}$ : There is a significant relationship between self-esteem and psychological wellbeing in adolescents.

$\mathbf{H}_{3}$ : Self-esteem is a significant mediator between parental attachment and psychological wellbeing in adolescents.

\section{Method}

The present study was conducted to examine the relationship between parental attachment, self-esteem, and psychological wellbeing in adolescents. The data was collected from December 2020 to February 2021. Adolescents in the age range of 13-18 years were selected. The adolescents living with both parents were selected. Adolescents below and above the age range $13-18$ years were excluded. Adolescents from families of single parent, divorced, step parents were not included in the study.

\section{Participants}

This study was conducted on adolescents from different private schools of the Jammu educational block. Using random sampling technique, 292 participants (male $=150$, female $=142$ ) were selected.

\section{Measures}

Inventory of parent and peer attachment-revised (IPPA-R) by Armsden and Greenberg (1987) ${ }^{13}$ : It is a self-reporting questionnaire with a five-point Likert scale response format: almost never or never true, not very often true, sometimes true, often true, and almost true or always true. The inventory comprises 25 items in each of the mother, father, and peer sections.

Self-esteem scale by Rosenberg $(1965)^{10}$ : It is a ten-item Likert scale with items answered on a four-point scale from strongly agree to strongly disagree. Five of the items have positively worded statements and five have negatively worded ones.

Psychological wellbeing scale by Ryff (1989) ${ }^{4}$ : The scale consists of 18 items. The items are divided into 6 dimensions that measure autonomy, environmental mastery, personal growth, relations with others, purpose in life, and self- 
acceptance. The subject is supposed to answer in a six-point format: (1) strongly disagree, (2) moderately disagree, (3) slightly disagree, (4) slightly agree, (5) moderately agree, and (6) strongly agree.

\section{Procedure}

Data was collected by visiting different private schools of Jammu educational block. Permission was taken from principals of selected schools for carrying out the research in their schools. Informed consent was taken from all the students before filling out the questionnaires. After getting permission and informed consent, questionnaires were given to the students. Filled out questionnaires were then collected, encoded, and analysed by Pearson's productmoment correlation method and mediation analysis by using Hayes ${ }^{22}$ process macro in SPSS 20.

\section{Results and Discussion}

The results presented in Table 1 reveal significant positive correlations between parental attachment and autonomy, environmental mastery, personal growth, purpose in life, and total psychological wellbeing. It is concluded that parental attachment is significantly associated with psychological wellbeing which provides evidence for supporting hypotheses stating there is a significant relationship between parental attachment and psychological wellbeing in adolescents. Similarly, positive correlations were found between self-esteem and autonomy, personal growth, positive relations with others, purpose in life, selfacceptance, and total psychological wellbeing. It implies that self-esteem is positively correlated with psychological wellbeing and its dimensions except for environmental mastery, providing support for hypotheses that states that there is a significant relationship between self-esteem and psychological wellbeing in adolescents.

To test for mediation of self-esteem, regression analysis was performed, by using procedures presented by Hayes. 22 Bootstrapping was set to 5000 resamples.

Parental attachment was positively associated with selfesteem ( $b=0.073, p<0.01$ ) which in turn was positively related with psychological wellbeing $(b=0.634, p<0.01)$. Self-esteem mediates, the association between parental attachment and psychological wellbeing $(b=0.111, p<$ 0.01 ) as compared to the total effect of parental attachment on psychological wellbeing $b=0.158, p<0.01$ ) reflecting partial mediation through self-esteem.

Table I.Relationship between Parental Attachment, Self-esteem, and Psychological Wellbeing in Adolescents

\begin{tabular}{|c|c|c|c|c|c|c|c|}
\hline Variables & Autonomy & $\begin{array}{c}\text { Environmental } \\
\text { Mastery }\end{array}$ & $\begin{array}{c}\text { Personal } \\
\text { Growth }\end{array}$ & $\begin{array}{c}\text { Positive } \\
\text { Relations } \\
\text { with Others }\end{array}$ & $\begin{array}{c}\text { Purpose } \\
\text { in Life }\end{array}$ & $\begin{array}{c}\text { Total } \\
\text { acceptance }\end{array}$ & $\begin{array}{c}\text { Psychological } \\
\text { Wellbeing }\end{array}$ \\
\hline $\begin{array}{c}\text { Parental } \\
\text { Attachment }\end{array}$ & $0.179^{*}$ & $0.200^{* *}$ & $0.172^{* *}$ & 0.087 & $0.216^{* *}$ & 0.077 & $0.306^{* *}$ \\
\hline Self-esteem & $0.136^{*}$ & 0.024 & $0.274^{* *}$ & $.211^{* *}$ & $0.128^{*}$ & $0.230^{* *}$ & $0.342^{* *}$ \\
\hline
\end{tabular}

Table 2.Mediating Role of Self-esteem on the Relationship between Parental Attachment and Psychological Wellbeing

\begin{tabular}{|c|c|c|c|c|}
\hline Model (Paths) & Coefficients & SE & t-value & Sig \\
\hline PA $\rightarrow$ PWB & 0.158 & 0.028 & 5.47 & 0.000 \\
\hline PA $\rightarrow$ SE & 0.073 & 0.012 & 6.07 & 0.000 \\
\hline SE $\rightarrow$ PWB & 0.634 & 0.134 & 4.70 & 0.000 \\
\hline PA $\rightarrow$ SE $\rightarrow$ PWB & 0.111 & 0.029 & 3.76 & 0.000 \\
\hline \multicolumn{2}{|c|}{ PA = Parental attachent, SE = Self- Esteem, PWB = Psychological wellbeing } \\
\hline
\end{tabular}

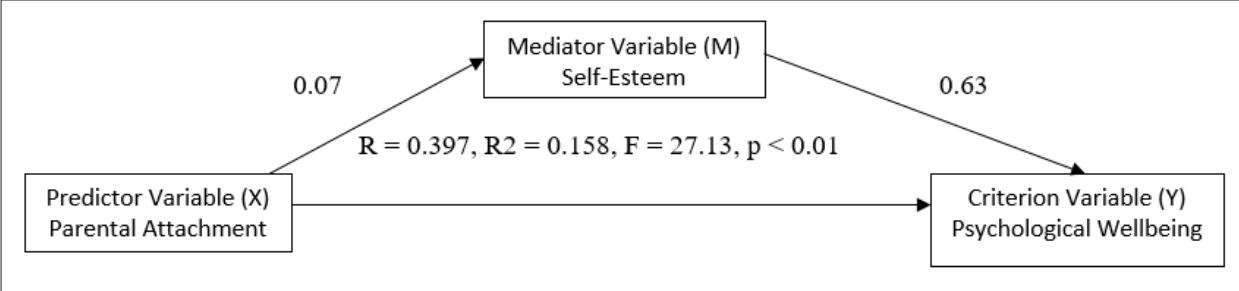

Figure I.Self-esteem as mediator of relationship between parental attachment and psychological wellbeing 
Approximately $39 \%$ of the variance in psychological wellbeing was accounted for by the predictors (R2 = 0.15). The indirect effect was calculated using a bootstrap estimation approach with 5000 samples. A significant indirect association was established $(b=0.04, \mathrm{SE}=0.01$; $95 \% \mathrm{Cl}=0.024-0.073$ ) and the findings indicated an indirect association between parental attachment and psychological wellbeing through self-esteem of adolescents. The results confirm the significant role of self-esteem as a partial mediator of parental attachment and psychological wellbeing. These results are consistent with the findings of Love and Murdock ${ }^{23}$ who reported a significant relationship between attachment to parents and psychological wellbeing. It was also confirmed that attachment was a significant predictor of psychological wellbeing. Freire and Tavare ${ }^{24}$ found that self-esteem had a strong and positive relationship with wellbeing among adolescents $(n=216)$ and self-esteem was found to be a significant predictor of wellbeing. Sadovnikova ${ }^{25}$ reported that there was a significant relationship between attachment to mother as well as father and adolescents' self-esteem. Lin and Mar $^{26}$ stated that adolescents who were highly attached to their parents reported greater satisfaction with themselves and less symptomatic response to stressful life events. Poudel, Gurung and Khanal ${ }^{21}$ also concluded that perceived social support indirectly affected the psychological wellbeing of adolescents through self -esteem as a mediating variable.

Warm and supportive parenting enhances the health and wellbeing of the adolescents. ${ }^{27}$ Both parent as well as peer attachment qualities appear to be related to psychological wellbeing in adolescence. ${ }^{13}$ High levels of parental involvement with adolescents are related to decreased chances of poor mental health among them. ${ }^{28}$ Similarly, self-esteem strengthens the feelings of wellbeing, approval, and success. ${ }^{29}$ Positive and warm parenting lets young people know that they are accepted as competent and worthwhile and enhances their self-esteem, ${ }^{9,13}$ and this self-esteem has been observed to be the most vital factor for retaining psychological wellbeing during adolescence. ${ }^{30}$

\section{Conclusion}

It is concluded that parental attachment and self-esteem are positively and significantly related to the psychological wellbeing of adolescents. Self-esteem partially mediates the relationship between parental attachment and psychological wellbeing.

As it occurs in every study, this research also has certain limitations. The sample size of the study was relatively small and thus the results cannot be generalised easily. The participants in the study are between the age of 13 and 18 years only. Other age groups can also be undertaken for the study. The findings are limited only to the quantitative analysis, as no qualitative analysis has been taken into consideration. Despite these limitations, the present study has certain implications for parents, school counsellors, teachers, and researchers to develop strategies to enhance adolescent's wellbeing. School counsellors could develop modules for workshops or group training sessions in which parents and guardians participate to learn different skills to help adolescents to develop their self-esteem which in turn will help to improve their psychological wellbeing. Wellbeing programs that incorporate primary prevention and intervention with an aim to increase the holistic development of adolescents should be introduced in the schools. The authorities of the schools could include the family and community in these programs.

\section{Authors' Contribution}

All authors have made substantial contributions to the conception and design of the study, analysis and interpretation of data, drafting the article, and revising it critically for important intellectual content, and final approval of the version.

\section{Acknowledgement}

The authors wish to extend special thanks to all the respondents who participated in the research.

\section{Source of Funding}

The authors did not receive any specific grant from funding agencies in the public,commercial or not-for-profit sectors.

\section{Conflict of Interest: None}

\section{References}

1. World Health Organization [Internet]. Adolescent Mental Health. 2012. Available from: www.who.int/ mental_health/publications/adolescent_mental_ health/en/

2. Reddy KR, Biswas A, Rao H. Assessment of mental health of Indian adolescents studying in urban schools. Malays J Paediatr Child Health. 2011;5. [Google Scholar]

3. Deci EL, Ryan RM. Hedonia, eudaimonia, and wellbeing: an introduction. J Happiness Stud. 2008;9(1): 1-11. [Google Scholar]

4. Ryff CD. Happiness is everything, or is it? Explorations on the meaning of psychological well-being. J Pers Soc Psychol. 1989;57(6):1069-81. [Google Scholar]

5. Perez JA. Gender Difference in Psychological Well-being among Filipino College Student Samples. Int J Humani Soc Sci. 2012;2(13):84-93. [Google Scholar]

6. Bowlby J. Attachment and Loss. Vol. 1. Attachment. New York: Basic Books; 1969.

7. Berk LE. Child development. 6th ed. Pearson Education; 2003.

8. Wel FV, Ogt BTT, Raaijmakers Q. Changes in the parental bond and the wellbeing of adolescents and young adults. Adolescence. 2002;37(146):317-33. 
9. Baron RA, Branscombe NR, Byrne DR, Bhardwaj G. Social Psychology. Pearson Education; 2010.

10. Rosenberg M [Internet]. Rosenberg Self-esteem Scale. 1965. Available from: www.yorku.ca/rokada/psyctest/ rosenbrg.pdf

11. Karatzias A, Chouliara Z, Power K, Swanson V. Predicting general well-being from self-esteem and affectivity: An exploratory study with Scottish adolescents. Qual Life Res. 2006;15(7):1143-51. [PubMed] [Google Scholar]

12. Pomerantz EM, Eaton MM. Developmental differences in children's conceptions of parental control: "They love me, but they make me feel incompetent". MerrillPalmer Quarterly. 2000;46:140-67. [Google Scholar]

13. Armsden GC, Greenberg MT. The inventory of parent and peer attachment: Individual differences and their relationship to psychological well-being in adolescence. J Youth Adolesc. 1987;16(5):427-54. [PubMed] [Google Scholar]

14. Yaacob MJB. Parent-adolescent relationships and its association to adolescents' self-esteem. Malays J Med Sci. 2006;13(1):21-4. [PubMed] [Google Scholar]

15. Anyanwu JI. Parental Relationship as a Correlate of Psychological Wellbeing of South Eastern Nigerian Adolescents. Afr J Teacher Edu. 2010;1(1):195-208. [Google Scholar]

16. Avci D, Yilmaz FA, Koç A. Correlation Between Subjective Well Being and Self-Esteem Levels of College Nursing Students. IAMURE: Int J Soc Sci. 2012;2(1):26-42. [Google Scholar]

17. Abubakar A, Alonso-Arbiol I, Van de Vijver FJR, Murugami M, Mazrui L, Arasa J. Attachment and psychological well-being among adolescents with and without disabilities in Kenya: The mediating role of identity formation. J Adolesc. 2013;36(5):849-57. [PubMed]

18. Nwankwo CB, Okechi BC, Nweke PO. Relationship between perceived self-esteem and psychological well-being among student athletes. Acad Res J Psychol Counsel. 2015;2(1):8-16. [Google Scholar]

19. Schilling K. Examining the Role of Self-esteem in the Association between Emotional Vulnerability and Psychological Well-being. Honors Theses [Internet]. 2015. Available from: http://ecommons. udayton. edu/uhp_theses/58

20. Bajaj B, Gupta R, Pande N. Self-esteem mediates the relationship between mindfulness and well-being. Perso Indi Diff. 2016;94:96-100. [Google Scholar]

21. Poudel A, Gurung B, Khanal GP. Perceived social support and psychological wellbeing among Nepalese adolescents: the mediating role of self-esteem. BMC Psychol. 2020;8(1):43. [PubMed] [Google Scholar]

22. Hayes AF. Introduction to mediation, moderation, and conditional process analyses. A regression-based approach. New York, NY: The Guilford Press; 2013.

23. Love KM, Murdock TB. Attachment to Parents and Psychological Well-Being: An Examination of Young Adult College Students in Intact Families and Stepfamilies. J Fam Psychol. 2004;18(4):600-8. [PubMed] [Google Scholar]

24. Freire T, Tavares D. Influence of self-esteem and emotion regulation in subjective and psychological well-being of adolescents: Contributions to clinical psychology. Arch Clin Psychiatry (São Paulo). 2011;38(5):184-8. [Google Scholar]

25. Sadovnikova T. Self-esteem and Interpersonal Relations in Adolescence. Procedia - Soc Behav Sc. 2016;233:4404.

26. Lin YY, Mar KK. A relationship between parent and peer attachment and psychological well-being of university students in late adolescence. Psychol [Internet]. 2016 [cited 23 March 2021]. Available from: https://www. semanticscholar.org/paper/A-Relationship-betweenParent-and-Peer-Attachment-Lin-Mar/6f56a0900989 3a20a5c8a48fd2f83f83499f5aa5

27. Clark AM. Family Communication Patterns and Adolescent Emotional Well-being: Cross Classification of Mother-child and Father-child Interactions [dissertation]. Oregon State University; 2015. [Google Scholar]

28. Hasumi T, Ahsan F, Couper CM, Aguayo JL, Jacobsen $\mathrm{KH}$. Parental involvement and mental well-being of Indian adolescents. Indian Pediatr. 2012;49(11):915-8. [PubMed] [Google Scholar]

29. Diener $E$, Diener $M$, Diener C. Factors predicting the subjective well-being of nations. J Pers Soc Psychol. 1995;69(5):851-64. [PubMed]

30. Winter DG. Personality: Analysis and interpretation of lives. McGraw-Hill; 1996. [Google Scholar] 